\title{
ABUNDÂNCIA ESPAÇO-TEMPORAL DO CAMARÃO DE ÀGUA DOCE MACROBRACHIUM AMAZONICUM (HELLER, 1862) (CRUSTACEA: PALAEMONIDAE) PROVENIENTE DO RIO GRANDE (DIVISA SP-MG), À JUSANTE DA USINA HIDROELÉTRICA ÀGUA VERMELHA
}

\author{
Rodrigues, L.R. ${ }^{1,}$; Carvalho, A.L.C. ${ }^{1}$; Costa, J.R.P. ${ }^{1}$; Nunes, J.S. ${ }^{1}$; Castilho, R.C.C. ${ }^{1}$; \\ Gomes, M.R.R.S. ${ }^{1}$ \& Andrade, L.S. ${ }^{1}$ \\ ${ }^{1}$ Universidade Federal do Triângulo Mineiro (UFTM), Campus Iturama, Grupo de Ensino, Pesquisa e Extensão \\ em Animais Aquáticos (GEPEAA). \\ *Autor correspondente: larissa-r-rodrigues@hotmail.com
}

\begin{abstract}
Conhecimentos sobre a relação entre o tempo, espaço e abundância dos indivíduos podem fornecer importantes dados sobre a estabilidade da população no ambiente em que se encontra. Esses dados favorecem a elaboração de planos de manejo e exploração racional, de modo que o recurso não se esgote ou desequilibre a comunidade bêntica. O presente trabalho objetivou avaliar a abundância espaço-temporal do camarão dulcícola Macrobrachium amazonicum no Rio Grande, em região à jusante da Usina Hidrelétrica de Água Vermelha, localizada na divisa entre os estados de São Paulo e Minas Gerais. Para tanto, os animais foram coletados mensalmente (Outubro de 2017 à Março de 2018) em 6 distintos pontos do Rio Grande, sendo o ponto 1 a mil metros e o ponto 6 à 4 mil metros. Uma peneira de saco, própria para camarões, foi arrastada 3 vezes, em giro de $180^{\circ}$ antes da colocação das armadilhas, as quais foram amarradas à margem do rio e deixadas em espera por aproximadamente 6 horas. Os animais coletados foram individualizados por método de coleta, ponto e mês. Em laboratório, foram sexados e o Comprimento do Cefalotórax (CC) foi mensurado. Para avaliação estatística, os dados foram logaritimizados e comparados por ANOVA. Um total de 6455 indivíduos foram capturados, sendo 4793 fêmeas (294 ovígeras), 1445 machos e 217 juvenis. A menor abundância ocorreu no mês de Janeiro com 761 espécimes e a maior em Outubro com 1740 espécimes, tendo por média mensal 1120 animais. Apesar da abundância temporal total parecer maior nos meses de 2017, não houve diferença significativa demonstrando uniformidade entre meses estudados. A abundância temporal de machos, fêmeas (ovígeras e não) também não diferiu na avaliação temporal $(p>0,05)$. Quanto à abundância espacial, o ponto de maior número de indivíduos foi o 4 e o de menor o 6, diferindo significativamente $(p=0,036)$. A abundância de fêmeas foi maior no ponto 2 com 119 indivíduos e menor no ponto 5 com apenas 2 . Diferiu nos pontos 1 e $6(p=0,013) ; 2$ e $6(p=, 0,015) ; 3$ e $6(p=0,004)$ e 4 e $6(p=0,003)$. Fêmeas ovígeras diferiram nos pontos 2 e $5(p=0.023)$ e pontos 2 e $6(p=0,034)$. O maior número de ovígeras coletadas nos pontos próximos às áreas mais antropizadas pode ser atribuída a possível disponibilidade de recurso alimentar e ausência de predadores. A abundância de machos foi semelhante em todos os pontos, mostrando dominância das fêmeas. A maior abundância nos pontos próximos à barragem pode ser relacionada preferência pelo substrato rochoso.
\end{abstract}

Palavras-chave: Caridea, Crustacea, desenvolvimento sustentável, plano de manejo. 